\title{
Knowledge Attitude and Practices of Patients Attending a Private Dental Hospital on Miswak
}

\author{
Shanthi Vanka ${ }^{*}$, Renad Otaif ${ }^{2}$, Samar Salah Hassan³, Hanan Abdul Almajeed Alhashdi ${ }^{3}$, \\ Eman Ali Alzahrani ${ }^{4}$, Othman Wali ${ }^{5}$, Amit Vanka ${ }^{1}$ and Sajda Khan Gajdhar ${ }^{1}$ \\ ${ }^{1}$ Faculty of Dentistry, Dentistry Program, Department of Preventive Dental Sciences, Ibn Sina National \\ College for Medical Studies, Jeddah, Saudi Arabia; shanthiamit@rediffmail.com, \\ amitvanka18@gmail.com,drsajdagajdhar@gmail.com \\ 2Dentist, Beauty Secrets Clinics, Najran, Saudi Arabia; renadotaif@gmail.com \\ ${ }^{3}$ Dental Intern, Dentistry Program, Department of Preventive Dental Sciences, Ibn Sina National College for \\ Medical Studies, Jeddah, Saudi Arabia; Samarreading@hotmail.com, lolosmart83@gmail.com \\ 4Dentist, Alnoor Specialist Hospital, Makkah, Saudi Arabia; eman.ali.alz2@gmail.com \\ ${ }^{5}$ Vice-Dean, Dentistry Program, Department of Oral Basic and Clinical Sciences, Ibn Sina National College \\ for Medical Studies, Jeddah, Saudi Arabia; oaakwali@yahoo.com
}

\begin{abstract}
Today, chewing sticks are being used commonly in the world. They are known by various names, including Miswak or arak in Arabic. The efficacy of Miswak and modern toothbrushes have shown a superior effect rather than use of toothbrush alone. This study aims to assess the Knowledge Attitude and Practices of patients attending a private dental hospital on Miswak. This is a cross-sectional analytical study. The study was conducted by means of a questionnaire, in order to obtain knowledge, attitude and practices of patients attending a private dental hospital on Miswak. An electronic copy of the questionnaire was prepared using Google forms in Arabic and distributed through social media. There were 342 respondents for the survey. About $93 \%$ of the participants selected that they use any oral hygiene aid as it is beneficial. Among all the participants only 2.3\% of them used Miswak as an oral hygiene aid and 31.6\% used both tooth brush and paste and Miswak. Majority of the respondents cleaned their teeth twice or thrice in a day. One of the main reasons of using Miswak by the participants was its religious background. The respondents prefer that the next generation would use a combination of Miswak and tooth brush.
\end{abstract}

Keywords: Attitude, Dental Clinics, Dental Patients, Knowledge, Miswak, Practices, Toothbrush

\section{Introduction}

Oral hygiene is one of the most important daily routine practices and keeps the mouth and teeth clean and prevents many health problems ${ }^{1}$. In this time when the electronic and manual brushes are most commonly used, still some use the traditional tooth cleaning aids ${ }^{2}$. Today, chewing sticks are being used commonly in the world. They are known by various names, including Miswak or arak in Arabic. The efficacy of Miswak and modern toothbrushes have shown a superior effect rather than the use of toothbrush alone. Miswak is a chewing stick used in many developing countries as a traditional toothbrush for oral hygiene ${ }^{3}$. It seems that Miswak is more beneficial than toothbrushes, toothpaste and mouthwashes ${ }^{4}$. Besides removing plaque, calculus, and debris it also provides the remedy to de-sensitize the teeth. The risk of dental caries identified was 9.35 times more in subjects using

${ }^{*}$ Author for correspondence 
toothbrushes than in those using chewing sticks. The use of Miswak was associated with a significant reduction of dental plaque and gingivitis along with comparable or superior oral hygiene effect ${ }^{4}$. In 1987, World Health Organization encouraged the developing nations to use Miswak for oral hygiene because of tradition, availability, and low $\operatorname{cost}^{5}$. The World Health Organization (WHO) has also recommended the use of Miswak as it is an effective tool for oral hygiene ${ }^{6}$.

The most common type of chewing stick, Miswak, is derived from Salvadora persica, a small tree or shrub with a spongy stem and root, which is easy to crush between the teeth ${ }^{7}$. Recently, various authors have concluded that chewing sticks or its extract have therapeutic effect on gingival diseases ${ }^{8}$. As a consequence, users of oral hygiene products now a days are again beginning to prefer natural components and a minimum of chemical additives in their toothpaste ${ }^{3}$. This study aims to assess the Knowledge Attitude and Practices of patients attending a private dental hospital on Miswak.

\section{Materials and Methods}

This is a cross-sectional analytical study that was conducted in a 15 days period in June 2020. The study was given an ethical approval from the IRRB of Ibn Sina National College for Medical Studies in Jeddah, Kingdom of Saudi Arabia. The Protocol identification number of the research is 012 SRC15052021 and the IRRB approval number is H-12-03062021. The consent from the participants has been taken before responding to the questionnaire. A convenient sampling technique was used to select participants in this study. The sample size of 246 was determined using the Raosoft online sample size calculator with a margin of error as $5 \%$, Confidence level as $95 \%$, considering the population size as 1000000 and response distribution to be $80 \%$. The selection criteria for the research was those patients willing to participate in the study and those patients above 18 years attending Ibn Sina Dental hospital clinics.

The study was conducted by means of a questionnaire. In order to obtain knowledge, attitude and practices of patients attending a private dental hospital on Miswak an electronic copy of the questionnaire was prepared using Google forms in Arabic and distributed through social media.

The questionnaire was be prepared after collecting data by asking three open ended questions on knowledge, attitude and practice of Miswak from the patients attending the dental clinics and from the study by Al-Hammadi 2018.

Then from the responses of the patients and study by Al-Hammadi 2018(3) a close ended questionnaire was prepared which was translated to Arabic for ease in understanding the questionnaire. The data gathered was kept confidential. Multiple choice questions were included in the questionnaire. The questionnaire had 4 questions (1 knowledge, 1 attitude and 2 practice) included for all participants then for Miswak users 8 questions (2 knowledge, 2 attitude and 4 practice based questions) were included in the questionnaire. Cronbach's alpha of the questionnaire was calculated from results and the value came to be $85 \%$. The responses were collected electronically using google docs. The google docs was distributed to all the patients using WhatsApp and other social media platforms. The statistical analysis was done using IBM SPSS version 23. The responses were represented as descriptive statistics in the form of numbers and percentages. Association between the variables was calculated using chi square test and $p$ value of less than 0.05 was considered statistically significant.

\section{Results}

There were 342 respondents for the survey. The mean age of the respondents was 31 . The table 1 describes the details of the sociodemographic of the participants. Occupation and family income came to be statistically significant when cross tabbed with gender of the participants. Table 2 describes the respondents perspective on the use of oral hygiene practices. There were $24.6 \%$ of the participants who brushed their teeth once, $35.7 \%$ twice, $34.8 \%$ thrice and $3.8 \%$ when ever required. The $93 \%$ of the participants selected the oral hygiene aid as it is beneficial. Among all the participants only $2.3 \%$ used Miswak as an oral hygiene aid and $31.6 \%$ used both tooth brush and paste and Miswak. Table 3 describes the responses of the users of only Miswak and the users of both Miswak and tooth brush \& paste. There were $8.6 \%$ of the respondents using Miswak due to cultural reasons, $60.3 \%$ using due to religious reasons, $3.4 \%$ due to cost, $2.1 \%$ availability and $15.5 \%$ using it due to scientific reasons. Ninety three percent respondents used any variety of Miswak that is available. The $6 \%$ of the respondents chew Miswak for minutes, $18.1 \%$ chew it till it turns like bristles and $7.8 \%$ any method. The feeling of $54.3 \%$ of the respondents is 
that after using Miswak they found the mouth to be fresh, $43.1 \%$ found their teeth to be whiter, $1.7 \%$ found no change and $0.9 \%$ found a bitterness and mouth acidity. Majority of the participants (42.2\%) stored Miswak by cutting the used end and storing it in the pocket. $40.5 \%$ of the participants used Miswak whenever required. The $88.8 \%$ of the participants responded that they would want the next generation to use a combination of Miswak and tooth brush.

\section{Discussion}

The present study is an analytical study that has been conducted among the patients attending the dental clinics of a private dental hospital. In a study by Bashir and Rizvi ${ }^{10}$ the response for the survey on oral hygiene practices was 86 males and 107 females. The study by Alshahrani et al. ${ }^{11}$ the response for the survey on oral hygiene practices was 291 (35.9) male and 519 female (64.1). The distribution of the participants in the study by Alshahrani et al. ${ }^{11}$ were graduates 561 (69.3) and postgraduate were 60(7.4) and in our study, there were 227 graduates and 19 postgraduates.
In the study conducted by Alshahrani et al. ${ }^{11}$ the participants frequency of cleaning the teeth was once by 274(33.8), twice by 272 (33.6) and whenever required cleaning was done by $90(11.1)$. Alhammadi et al. ${ }^{3}$ reported in his study $28.2 \%$, of the participants cleaned their teeth once $37.6 \%$, twice, $28.4 \%$, whenever required and $5.9 \%$ infrequently which is almost the same as our study in which the percentages are $24 \%$ once and $35.7 \%$ twice.

In a study by Alshahrani et al. ${ }^{11}$, toothbrush and paste was used by 501(61.9\%), Miswak by 28 (3.5\%) and $17(2.1 \%)$ didn't brush their teeth.

Strong evidence from clinical trials suggests that Miswak is a very potent oral hygiene tool due to its mechanical plaque removing efficiency and its biological properties $^{12}$. Optimum use of Miswak depends on its regular use in the right technique. And studies suggest that participants knowledge is not optimum about Miswak. So strategies to increase the knowledge of the community should be planned at an individual and community level.

In our study the use of Miswak along with tooth brush \& paste was more used by the participants. The use of both tooth brush and Miswak suggests that access to all surfaces of the oral cavity would result in good oral

Table 1. Socio demographic details of the study participants

\begin{tabular}{|c|c|c|c|c|c|}
\hline Independent variables & Male N (\%) & Female N (\%) & Total N (\%) & Chi square & p value \\
\hline \multicolumn{6}{|l|}{ Education } \\
\hline Not educated & $1(1.7)$ & $2(0.7)$ & $3(0.9)$ & \multirow{4}{*}{5.909} & \multirow{4}{*}{.116} \\
\hline $10^{\text {th }}$ class pass & $14(23.3)$ & $79(28)$ & $93(27.2)$ & & \\
\hline Graduated & $38(63.3)$ & $189(67.0)$ & $227(66.4)$ & & \\
\hline Post graduation and higher & $7(11.7)$ & $12(4.3)$ & $19(5.6)$ & & \\
\hline \multicolumn{6}{|l|}{ Occupation $^{\star}$} \\
\hline Employed & $46(76.7)$ & $83(29.4)$ & $129(37.7)$ & \multirow{3}{*}{47.029} & \multirow{3}{*}{0.00} \\
\hline Unemployed & $8(13.3)$ & $105(13.3)$ & $113(33.0)$ & & \\
\hline Student & $6(10.0)$ & $94(33.3)$ & $100(29.2)$ & & \\
\hline \multicolumn{6}{|l|}{ Nationality } \\
\hline Saudi & $31(51.7)$ & $169(59.9)$ & $200(58.5)$ & \multirow{2}{*}{1.391} & \multirow[b]{2}{*}{.238} \\
\hline Non-Saudi & $29(48.3)$ & $113(40.1)$ & $142(41.5)$ & & \\
\hline \multicolumn{6}{|l|}{ Family income ${ }^{\star}$} \\
\hline$(<3000)$ & $5(8.3)$ & $39(13.8)$ & $44(12.9)$ & \multirow{5}{*}{13.564} & \multirow{5}{*}{.019} \\
\hline$(3000-5000)$ & $16(26.7)$ & $64(22.7)$ & $80(23.4)$ & & \\
\hline$(5000-7000)$ & $18(30.0)$ & $37(13.1)$ & $55(16.1)$ & & \\
\hline$(7000-10000)$ & $0(0.0)$ & $2(0.7)$ & $2(0.6)$ & & \\
\hline$(>10000)$ & $16(26.7)$ & $93(33.0)$ & $109(31.9)$ & & \\
\hline Total & $282(82.5)$ & $60(17.5)$ & $342(100)$ & & \\
\hline
\end{tabular}

${ }^{\star} \mathbf{p}<0.05$ (statistically significant) 
Table 2. Respondents perspective on the use of oral hygiene practices

\begin{tabular}{|c|c|c|c|c|c|}
\hline Independent variables & Male N (\%) & Female N (\%) & Total N (\%) & Chi square & p value \\
\hline \multicolumn{6}{|c|}{ How many times do you clean your teeth? ${ }^{\star}$ (Practice) } \\
\hline Once & $13(21.7)$ & $69(24.5)$ & $82(24.6)$ & \multirow{4}{*}{13.822} & \multirow{4}{*}{.008} \\
\hline Twice & $11(18.3)$ & $111(39.4)$ & $122(35.7)$ & & \\
\hline Thrice & $31(51.7)$ & $88(31.2)$ & $119(34.8)$ & & \\
\hline Whenever required & $4(6.7)$ & $88(31.2)$ & $13(3.8)$ & & \\
\hline \multicolumn{6}{|c|}{ How do you select the oral hygiene aid? (Attitude) } \\
\hline It is beneficial & $57(95.0)$ & $261(92.6)$ & $318(93.0)$ & \multirow{2}{*}{454} & \multirow{2}{*}{.500} \\
\hline I don't trust any other method & $3(5.0)$ & $21(7.4)$ & $24(7.6)$ & & \\
\hline \multicolumn{6}{|c|}{ What is the primary oral hygiene method you use? (Practice) } \\
\hline Toothbrush and paste & $36(60.0)$ & $185(65.6)$ & $221(64.6)$ & \multirow{4}{*}{2.912} & \multirow{4}{*}{.573} \\
\hline Miswak & $2(3.3)$ & $6(2.1)$ & $8(2.3)$ & & \\
\hline Both of them & $21(35.0)$ & $87(30.9)$ & $108(31.6)$ & & \\
\hline Any other & $1(1.7)$ & $1(0.4)$ & $2(0.6)$ & & \\
\hline None & $0(0.0)$ & $3(1.1)$ & $3(0.9)$ & 2.912 & .573 \\
\hline \multicolumn{6}{|c|}{ Is tooth brushing or any other method more beneficial than Miswak? (Knowledge) } \\
\hline Yes & $43(71.7)$ & $185(65.6)$ & $228(66.7)$ & \multirow{2}{*}{.819} & \multirow{2}{*}{.366} \\
\hline No & $17(28.3)$ & $97(34.4)$ & $114(33.3)$ & & \\
\hline Total & $282(82.5)$ & $60(17.5)$ & $342(100)$ & & \\
\hline
\end{tabular}

${ }^{*} \mathbf{p}<0.05$ (statistically significant)

Table 3. Responses of the Miswak users

\begin{tabular}{|c|c|c|c|c|c|}
\hline Independent variables & Male N (\%) & Female N (\%) & Total N (\%) & Chi square & p value \\
\hline \multicolumn{6}{|c|}{ What is the primary oral hygiene method you use? (Practice) } \\
\hline Both Tooth brush and toothpaste and Miswak & $21(91.3)$ & $87(93.5)$ & $108(93.1)$ & \multirow{2}{*}{0.145} & \multirow{2}{*}{0.704} \\
\hline Miswak & $2(8.7)$ & $6(6.5)$ & $8(6.9)$ & & \\
\hline \multicolumn{6}{|l|}{ Why do you use Miswak? * (Knowledge) } \\
\hline Cultural reasons & $3(13)$ & $7(7.5)$ & $10(8.6)$ & \multirow{5}{*}{13.705} & \multirow{5}{*}{0.008} \\
\hline Religious reasons & $8(34.8)$ & $62(66.7)$ & $70(60.3)$ & & \\
\hline Cost & $3(13)$ & $1(1.1)$ & $4(3.4)$ & & \\
\hline Availability & $5(21.7)$ & $9(9.7)$ & $14(2.1)$ & & \\
\hline Scientific reasons & $4(17.4)$ & 1415.1) & $18(15.5)$ & & \\
\hline \multicolumn{6}{|l|}{ What type of Miswak do you use? (Practice) } \\
\hline Any variety available & $22(95.7)$ & $86(92.5)$ & $108(93.1)$ & \multirow{4}{*}{1.077} & \multirow{4}{*}{0.783} \\
\hline A particular variety & $1(4.3)$ & $3(3.2)$ & $4(3.4)$ & & \\
\hline Arak & $0(0.0)$ & $3(3.2)$ & $3(2.6)$ & & \\
\hline Black toothpick & $0(0.0)$ & $1(1.1)$ & $1(0.9)$ & & \\
\hline \multicolumn{6}{|l|}{ How do you use Miswak? (Practice) } \\
\hline Chew it for minutes & $1(4.3)$ & $6(6.5)$ & $7(6)$ & \multirow{4}{*}{7.248} & \multirow{4}{*}{0.064} \\
\hline Chew it till it turns like bristles & $0(0.0)$ & $21(22.6)$ & $21(18.1)$ & & \\
\hline Taper it and use it like a brush & $19(82.6)$ & $60(64.5)$ & $79(68.1)$ & & \\
\hline Any other method & $3(13)$ & $6(6.5)$ & $9(7.8)$ & & \\
\hline
\end{tabular}




\begin{tabular}{|c|c|c|c|c|c|}
\hline \multicolumn{6}{|c|}{ What is the feeling after the use of Miswak? ${ }^{\star}$ (Attitude) } \\
\hline Fresh & $9(39.1)$ & $54(58.1)$ & $63(54.3)$ & \multirow{4}{*}{13.496} & \multirow{4}{*}{0.004} \\
\hline Teeth are whiter & $11(47.8)$ & $39(41.9)$ & $50(43.1)$ & & \\
\hline No change & $2(8.7)$ & $0 .(0.0)$ & $2(1.7)$ & & \\
\hline Bitterness and mouth acidity & $1(4.3)$ & $0(0.0)$ & $1(0.9)$ & & \\
\hline \multicolumn{6}{|l|}{ How do you store Miswak? ${ }^{\star}$ (Knowledge) } \\
\hline In my pocket/Bag exposed to air & $8(8.6)$ & $3(13)$ & $11(9.5)$ & \multirow{4}{*}{8.229} & \multirow{4}{*}{0.042} \\
\hline In my pocket/Bag covered & $25(26.9)$ & $2(8.7)$ & $27(23.3)$ & & \\
\hline Cut used end and store it in the pocket & $15(65.2)$ & $34(36.6)$ & $49(42.2)$ & & \\
\hline Single use and discard & $3(13)$ & $26(28)$ & $29(25)$ & & \\
\hline \multicolumn{6}{|c|}{ How many times do you use Miswak in a day? ${ }^{*}$ (Practice) } \\
\hline Once & $0(0.0)$ & $22(23.7)$ & 22(19) & \multirow{5}{*}{20.388} & \multirow{5}{*}{0.000} \\
\hline Twice & $1(4.3)$ & $15(16.1)$ & $16(13.8)$ & & \\
\hline Thrice & $11(47.8)$ & $11(11.8)$ & $22(19)$ & & \\
\hline Whenever required & $10(43.5)$ & $37(39.8)$ & $47(40.5)$ & & \\
\hline Infrequently & $1(4.3)$ & $8(8.6)$ & $9(7.8)$ & & \\
\hline \multicolumn{6}{|c|}{ I will prefer the next generation to use ${ }^{*}$ (Attitude) } \\
\hline Miswak only & $1(4.3)$ & $1(1.1)$ & $2(1.7)$ & \multirow{3}{*}{6.405} & \multirow{3}{*}{0.041} \\
\hline Toothbrush and paste & $5(21.7)$ & $6(6.5)$ & $11(9.5)$ & & \\
\hline Combination of Miswak and toothbrush & $86(92.5)$ & $17(73.9)$ & $103(88.8)$ & & \\
\hline Total & $93(80.2)$ & $23(19.8)$ & $116(100)$ & & \\
\hline
\end{tabular}

\section{${ }^{*} \mathrm{p}<0.05$ (statistically significant)}

hygiene maintenance ${ }^{12}$. Our study results are in line with the study results of Alhammadi et al. ${ }^{3}$ in which religious reason is the main reason for the use of Miswak. In our study the respondents used any variety of Miswak that was available but in the study by Alhammadi et al. ${ }^{3}$ nearly half of the respondents used any variety and half used a particular variety. Both our study and the study by Alhammadi et al. ${ }^{3}$ respondents found fresh feeling after using Miswak. In our study the respondents store Miswak after they cut the used end and stored in the pocket in contrast to the study by Alhammadi et al. ${ }^{3}$ where they put it in the pocket in a bag exposed to air. In both the studies the respondents preferred that the next generations use both the combination of Miswak and toothbrush.

In the study by Bashir and Rizvi ${ }^{10}, 28.1 \%$ participants had adequate Knowledge and $71.9 \%$ did not have sufficient knowledge on primary oral hygiene method used and type of Miswak. So efforts should be directed towards increasing the knowledge of the community through various strategies. Barriers of its use also have to be broken and emphasis on use of Miswak along with brushing may be reinforced. And most importantly World
Health Organization ${ }^{13}$ has recommended and encouraged Miswak as a tool of oral hygiene in areas where its use is customary; and Saudi Arabia being one such country we have to play a very important role in promoting its use in oral hygiene maintenance.

Dentists have a role to play in educating the public at both clinical and community level. At a clinical level all the patients who visit the clinics/hospitals have to be educated about the importance of Miswak as an oral hygiene aid and the method of its use. It is also important to promote the use of both Miswak and tooth brushing as oral hygiene aids. Dentists also play a very important role in promoting the oral health of the community. So health education of the community on the importance of Miswak has to be imparted to promote the health using an oral hygiene aid with a cultural and religious background. Emphasis also has to be placed in educating the community on the right technique of using Miswak. Monitoring of effective planning of the programs periodically are very essential in successful promotion of the use of Miswak. 
Government also should provide various training for the dentists in increasing their awareness in promoting Miswak alongside the use of other oral hygiene aids like the toothbrush. The role of Miswak as an oral hygiene may be included into the curriculum along with the tooth brushing at the level of University for the dental students. We would like to emphasize on the importance of the use of Miswak by the community as it has a very important religious and a strong scientific background in its use for maintenance of good oral hygiene.

\section{Conclusion}

The conclusion of our study is that majority of the respondents clean their teeth twice or thrice in a day, one of the main reasons of using Miswak is its religious background. The respondents used Miswak whenever required and had the feeling of fresh breath. After its use, they stored it by cutting the used end for its reuse. Most importantly the respondents wants to see the continuation of the tradition and use of Miswak with tooth brush.

\section{References}

1. Halawany HS. A review on Miswak (Salvadora Persica) and its effect on various aspects of oral health. Saudi Dent J. 1 Apr 2012; 24(2): 63-9. https://doi.org/10.1016/j. sdentj.2011.12.004

2. Al Otaibi M, Al-Harthy M, Gustafsson A, Johansson A, Claesson R, Angmar-Månsson B. Subgingival plaque microbiota in Saudi Arabians after use of Miswak chewing stick and toothbrush. J Clin Periodontol. 31 Dec 2004 (12): 104853. https://doi.org/10.1111/j.1600-051X.2004.00618.x

3. Al-Hammadi AA, Al-Rabai NA, Togoo RA, Zakirulla M, Alshahrani I, Alshahrani A. Knowledge, attitude, and behavior related to use of Miswak (Chewing Stick): A cross-sectional study from aseer region, Saudi Arabia.
Contemporary clinical dentistry. Jun 2018; 9(Suppl 1): S64. https://doi.org/10.4103/ccd.ccd_45_18

4. Nordin A, Saim AB, Ramli R, Hamid AA, Nasri NW, Idrus RB. Miswak and oral health: An evidence-based review. Saudi J. Biol. Sci. 2020 1; 27(7): 1801-10. https://doi. org/10.1016/j.sjbs.2020.05.020

5. Wu CD, Darout IA, Skaug N. Chewing sticks: timeless natural toothbrushes for oral cleansing. J Periodontal Rest of the examination is unchanged from previous evaluation. 2001; 36(5): 275-84. https://doi.org/10.1034/ j.1600-0765.2001.360502.x

6. Dahiya P, Kamal R, Luthra RP, Mishra R, Saini G. Miswak: A periodontist's perspective. J. Ayurveda Integr. Med. 2012; 3(4): 184. https://doi.org/10.4103/0975-9476.104431

7. Patel PV, Shruthi S, Kumar S. Clinical effect of Miswak as an adjunct to tooth brushing on gingivitis. J Indian Soc Periodontol. 2012; 16: 84-8. https://doi.org/10.4103/0972124X.94611

8. Al-Obaida MI, Al-Essa MA, Asiri AA, Al-Rahla AA. Effectiveness of a $20 \%$ Miswak extract against a mixture of Candida albicans and Enterococcus faecalis. Saudi Med J. 2010; 31: 640-3.

9. Raosoft I. Sample size calculator by Raosoft, Inc.

10. Bashir R, Rizvi K. Assessment of levels of oral hygiene awareness, knowledge, attitude and practice among the students of a government school in Karachi. Journal of Advances in Medicine and Medical Research. 2016 16: 1-1. https://doi.org/10.9734/BJMMR/2016/24794

11. Alshahrani S, Alshuaibi A, Alkhaldi M, Koppolu P. Perception and Knowledge of Patients from Different Regions in the Kingdom of Saudi Arabia towards Oral Hygiene and Oral Hygiene Aids. In Healthcare 2021 May (Vol. 9, No. 5, p. 592). Multidisciplinary Digital Publishing Institute. https://doi.org/10.3390/healthcare 9050592

12. Haque MM, Alsareii SA. A review of the therapeutic effects of using Miswak (Salvadora Persica) on oral health. S Saudi Med. J. May 2015; 36(5): 530. https://doi.org/10.15537/ smj.2015.5.10785

13. World Health Organization. Prevention of oral diseases. World Health Organization; 1987. 